\title{
Ocean Salinity as a Precursor of Summer Rainfall over the East Asian Monsoon Region
}

\author{
BIAO CHEN \\ State Key Laboratory of Tropical Oceanography, South China Sea Institute of Oceanology, Chinese Academy of Sciences, \\ Guangzhou, and Graduate School, University of Chinese Academy of Sciences, Beijing, China \\ HuILING QIN \\ School of Atmospheric Sciences, Sun Yat-sen University, Guangzhou, and Southern Marine Science \\ and Engineering Guangdong Laboratory (Zhuhai), Zhuhai, China

\section{GUIXING CHEN} \\ School of Atmospheric Sciences, and Guangdong Province Key Laboratory for Climate Change and Natural Disaster \\ Studies, Sun Yat-sen University, Guangzhou, and Southern Marine Science and Engineering Guangdong Laboratory \\ (Zhuhai), Zhuhai, China

\section{HUIJIE XUE} \\ State Key Laboratory of Tropical Oceanography, South China Sea Institute of Oceanology, Chinese Academy of \\ Sciences, Guangzhou, China, and School of Marine Sciences, University of Maine, Orono, Maine
}

(Manuscript received 2 November 2018, in final form 25 March 2019)

\begin{abstract}
The sea surface salinity (SSS) varies largely as a result of the evaporation-precipitation difference, indicating the source or sink of regional/global water vapor. This study identifies a relationship between the spring SSS in the tropical northwest Pacific (TNWP) and the summer rainfall of the East Asian monsoon region (EAMR) during 1980-2017. Analysis suggests that the SSS-rainfall link involves the coupled ocean-atmosphere-land processes with a multifacet evolution. In spring, evaporation and water vapor flux divergence were enhanced in some years over the TNWP where an anomalous atmospheric anticyclone was established and a high SSS was well observed. As a result, the convergence of water vapor flux and soil moisture over the EAMR was strengthened. This oceanto-land water vapor transport pattern was sustained from spring to summer and played a leading role in the EAMR rainfall. Moreover, the change in local spring soil moisture helped to amplify the summer rainfall by modifying surface thermal conditions and precipitation systems over the EAMR. As the multifacet evolution is closely related to the large-scale ocean-to-land water vapor transport, it can be well represented by the spring SSS in the TNWP. A random forest regression algorithm was used to further evaluate the relative importance of spring SSS in predicting summer rainfall compared to other climate indices. As the SSS is now monitored routinely by satellite and the global Argo float array, it can serve as a good metric for measuring the water cycle and as a precursor for predicting the EAMR rainfall.
\end{abstract}

\section{Introduction}

The East Asian monsoon region (EAMR) is located to the west of the North Pacific Ocean, covering China, the Korean Peninsula, and Japan $\left(15^{\circ}-45^{\circ} \mathrm{N}, 100^{\circ}-140^{\circ} \mathrm{E}\right)$. It receives substantial rainfall during the boreal summer when monsoon flow transports a large amount of water

Corresponding author: Huijie Xue, huijiexue@scsio.ac.cn vapor from the ocean to the continent (Lau and Li 1984; Webster and Yang 1992; Ding and Chan 2005; Zhang and Zhou 2015). However, the monsoon rainfall varies from year to year because of the anomalous large-scale atmospheric circulation and underlying surface conditions both over the ocean and on the land (Xue et al. 2004; Zhou and Yu 2005; Gao et al. 2015; Dong et al. 2016; Chiang et al. 2017; Hu et al. 2017). The resultant severe floods/droughts strongly affect the regional hydrologic 
cycle over the EAMR (Wang and LinHo 2002; G. Chen et al. 2017). Further understanding and prediction of the variations of summer rainfall over the EAMR have been a key scientific issue and also have valuable implications for society (Huang and Sun 1992; Webster and Yang 1992; Wang et al. 2000; Wu et al. 2009).

Much effort has been devoted to searching for the suitable predictors of summer rainfall over the EAMR in past decades. Zhou and $\mathrm{Yu}$ (2005) found that the large-scale atmospheric circulation can transport water vapor from seas adjacent to the EAMR, which is a key process of the East Asia monsoon system. Besides the external source of water vapor, soil moisture is another important parameter in the hydrological cycle of the East Asia monsoon system (Yang and Lau 1998; Kim and Hong 2007; Zhang et al. 2011). Because of the large water capacity of soil, the seasonal moisture signal can be stored and released slowly (Guo et al. 2011; Zuo and Zhang 2016). For instance, the springtime soil moisture can represent the storage of local water vapor, which can provide crucial initial conditions for the following summer rainfall of the EAMR (Liu et al. 2017). These indicate that the terrestrial climate over the EAMR can be strongly modulated both by the adjacent oceans through the atmospheric circulation and by the subsequent feedback through the water cycle on land. Understanding the physical mechanisms of water cycle across seasons and regions is important to improving the prediction of summer rainfall over the EAMR (Wang and LinHo 2002). Although the large-scale atmospheric circulation patterns have been well studied (Lau and $\mathrm{Li}$ 1984; He et al. 2017), the impact of water vapor transport from adjacent seas to EAMR is less understood. In particular, how to measure this water cycle for explaining the predictive value of regional climate is still a key question to be addressed.

Evidence shows that the origins of the continental precipitation are closely related with the variations of the ocean (Schmitt 2008). The ocean provides about $86 \%$ of the evaporation and receives about $78 \%$ of the precipitation globally, which implies its important role in regulating continental precipitation (Schmitt 1995; Yu et al. 2017). Besides, the ocean surface evaporationprecipitation flux is highly correlated with the sea surface salinity (SSS) in climatological sense, especially in the subtropical oceans where evaporation and precipitation are predominant in regulating the SSS (Gordon et al. 2015). As the variation of ocean salinity can be observed more accurately than the evaporation or precipitation, the SSS observation can provide a reliable metric of the source/sink of water vapor (Yu 2011). In recent years, various salinity datasets have been derived from in situ and satellite observations, thus the SSS as an indicator of large-scale water source is now feasible. Using a long-term archive of SSS data can illustrate the water cycle and its change and provide insights into the role of ocean salinity in climate systems (Yu 2011; Durack 2015).

Several recent studies have used the ocean salinity to study the oceanic role in hydrological cycle and to predict the rainfall in the adjacent regions. Using Aquarius satellite data, Bingham and Lee (2017) investigated the spatial-temporal scales of SSS between $60^{\circ} \mathrm{S}$ and $60^{\circ} \mathrm{N}$ and found that the SSS variation in tropics along the intertropical convergence zones is the largest among all oceans in spatial scales. Li et al. (2016a,b, 2018) demonstrated the predictive value of the SSS in the adjacent subtropical seas on the seasonal rainfall in the U.S. Midwest and Sahel region and discussed the physical link between them. Nagano et al. (2017) revealed the coupled variations of SSS and freshwater flux in the western Pacific and found the impact of ENSO-scale freshwater flux variation on SSS in this region. Liu et al. (2018) investigated the teleconnection between the global autumn SSS signals and the winter precipitation in the southwestern United States and found that the SSS-based model has a better performance than the SST-based model. Zeng et al. (2019) revealed that the spring SSS signal in the South China Sea has a high correlation with the summer rainfall over the Yangtze River valley, and the signal can be used as a predictor of the summer rainfall. Although the tropical northwest Pacific (TNWP) is well recognized as one of the main sources of water vapor for the EAMR (Wei et al. 2012; Pan et al. 2017), our knowledge of the physical connection between the SSS there and the EAMR summer rainfall is still lacking.

The purpose of this study is to address whether the SSS in the TNWP can signal the regional water cycle of the EAMR. To meet the societal needs for forecasting precipitation with as much lead time as possible, we pay more attention to the spring SSS and its connection to the EAMR summer rainfall. For this purpose, we first examine the physical processes by which the spring SSS in the TNWP plays in the EAMR water cycle. We then use a predictive model to evaluate a variety of climate indices as well as the SSS regarding their predictive skills of summer rainfall over the EAMR. The observed SSSrainfall link will be presented in a multifacet evolution, that is, the sustained transport of water vapor to the EAMR in spring-summer as signaled by the SSS in the TNWP (section 3) and the contribution of the springtime soil moisture over the EAMR to the following summer rainfall (section 4). The importance of SSS relative to other indices for the prediction of summer rainfall in the EAMR is further shown in section 5. Conclusions and discussion are provided in the final section. 
TABLE 1. The list of data used in this study.

\begin{tabular}{llrr}
\hline \multicolumn{1}{c}{ Name } & \multicolumn{1}{c}{ Source } & Spatial resolution & Temporal range/resolution \\
\hline $\begin{array}{l}\text { Surface salinity } \\
\begin{array}{l}\text { Precipitation } \\
\text { Soil moisture, wind, water vapor flux, }\end{array}\end{array}$ & EN4.2.1 (UKMO) & $1^{\circ} \times 1^{\circ}$ & Jan 1980-Dec 2017/monthly \\
$\quad$ geopotential height, sensible heat flux, & CPC & $0.5^{\circ} \times 0.5^{\circ}$ & Jan 1980-Dec 2017/monthly \\
$\begin{array}{l}\text { latent heat flux, near-surface specific } \\
\text { humidity, and 2-m air temperature }\end{array}$ & ERA-Interim & $0.25^{\circ} \times 0.25^{\circ}$ & Jan 1980-Dec 2017/monthly \\
\begin{tabular}{l} 
Precipitation \\
\hline
\end{tabular} & PR 3A25 (TRMM) & $0.5^{\circ} \times 0.5^{\circ}$ & Jan 1998-Dec 2014/monthly \\
\hline
\end{tabular}

\section{Data and methods}

\section{a. Datasets of ocean salinity, terrestrial rainfall, soil moisture, and atmospheric reanalysis}

To quantify the interannual variability of SSS, we use the salinity reanalysis data (EN.4.2.1) from the Met Office (UKMO; Good et al. 2013). The salinity data are composed of the World Ocean Database 2005, Argo database, and data from the Global Temperature and Salinity Profile Program (GTSPP) with quality assessment and control (Good et al. 2013). The EN4.2.1 dataset are updated with the up-to-date GTSPP and Argo collections, and the objectively analyzed data with $1^{\circ} \times 1^{\circ}$ spatial resolution are available to users on request (Good et al. 2013). In this study, the SSS refers to the 5-m depth salinity of EN.4.2.1.

In this study, we use the daily precipitation dataset at $0.5^{\circ} \times 0.5^{\circ}$ resolution provided by the National Oceanic and Atmospheric Administration's (NOAA) Climate Prediction Center (CPC; Xie 2010) Unified Precipitation Project to depict terrestrial rainfall. Integrating satellite measurements with available in situ observations, the dataset exhibits an improved accuracy and interproduct consistency. The precipitation patterns derived from the dataset also show a good agreement with those in several gauge-based datasets (Xie 2010). The summer rainfall is analyzed using empirical orthogonal functions (EOF) to depict the main patterns and interannual variations over the EAMR. To distinguish the contributions of thermodynamic factors to large-scale precipitation and local convective precipitation, we also utilize another monthly dataset: the Tropical Rainfall Measuring Mission Precipitation Radar (TRMM PR 3A25) at $0.5^{\circ}$ horizontal resolution from 1998 to 2014. The satellite data are used to analyze the relative contribution from convective precipitation to total rainfall amount.

To examine the linkage between spring SSS and summer rainfall, we use the gridded soil moisture data from the European Centre for Medium-Range Weather Forecasts interim reanalysis (ERA-Interim; Dee et al. 2011). Previous studies (e.g., Scipal et al. 2008) have demonstrated a high consistency of this dataset with observations for both spatial and temporal features. In particular, the comparison between these soil moisture data with in situ observations over the EAMR suggested the fidelity of this soil moisture dataset (Zuo and Zhang 2009). In this study, the soil moisture refers to the overall average of four volumetric layers of soil water $(0-7$, $7-28,28-100$, and $100-289 \mathrm{~cm}$ ).

To analyze atmospheric circulation, we also use the vertically integrated (1000-100 $\mathrm{hPa})$ eastward and northward water vapor fluxes, the divergence of moisture fluxes, surface sensible and latent heat fluxes, 2-m air temperature, near-surface specific humidity, and the geopotential at $850 \mathrm{hPa}$ from ERA-Interim. The vertical velocity at $500 \mathrm{hPa}$ is also used to represent the ascending motion in the troposphere. It should be noted that the positive (negative) values of the vertical velocity represent the ascending (descending) motions in this study. All these variables from ERA-Interim are monthly and have a horizontal resolution of $0.25^{\circ} \times 0.25^{\circ}$.

In this study, we focus on the period from January 1980 to December 2017 when most of the above monthly datasets are available (Table 1). Anomalies are derived by subtracting the climatological mean of 1980-2017 of corresponding months. To analyze the interannual variations of spring SSS and summer rainfall, the SSS index is defined as the March-May (MAM) SSS anomaly (SSSa) averaged over a key region in the TNWP, and the summer rainfall index is the first principal component of the EOF analysis of June-August (JJA) rainfall over the EAMR after applying a high-pass Butterworth filter shorter than 7 years to extract the interannual variation.

\section{b. Random forest regression for predicting the summer rainfall over EAMR}

To evaluate the value of TNWP SSS for predicting the EAMR rainfall, we employ the random forest regression algorithm (RFRA). RFRA is a commonly used method of machine learning that allows for training samples be added constantly to create decision trees and finally produce a predictive model (Breiman 2001). Teleconnections have been investigated between the summer rainfall over the EAMR and climate indices, such as the Antarctic Oscillation (AAO; e.g., Sun et al. 
TABLE 2. SSS index and six climate indices used for the predictive model. Note: The number of -1 in the third column represents the preceding year.

\begin{tabular}{|c|c|c|}
\hline Index & Description & $\begin{array}{l}\text { The maximum correlation } \\
\text { month/lead time }\end{array}$ \\
\hline Tropical northwest Pacific SSS & $\begin{array}{l}\text { Averaged SSS anomaly by subtracting the } \\
\text { climatological mean during } 1980-2017 \\
\text { over the key region }\left(5^{\circ}-20^{\circ} \mathrm{N}, 120^{\circ}-140^{\circ} \mathrm{E}\right)\end{array}$ & Mar-May/3 months \\
\hline Niño-3.4 & $\begin{array}{l}\text { SSTA over the eastern Pacific }\left(5^{\circ} \mathrm{S}-5^{\circ} \mathrm{N} \text {, }\right. \\
\left.170^{\circ}-120^{\circ} \mathrm{W}\right)\end{array}$ & Dec $(-1)-F e b / 6$ months \\
\hline Dipole mode index (DMI) & $\begin{array}{l}\text { SSTA between the tropical western Indian } \\
\text { Ocean }\left(10^{\circ} \mathrm{S}-10^{\circ} \mathrm{N}, 50^{\circ}-70^{\circ} \mathrm{E}\right) \text { and the } \\
\text { tropical southeastern Indian Ocean } \\
\left(10^{\circ} \mathrm{S} \text {-equator, } 90^{\circ}-110^{\circ} \mathrm{E}\right)\end{array}$ & May/1 month \\
\hline North Atlantic Oscillation (NAO) & $\begin{array}{l}\text { Differences in sea level pressure between } \\
\text { Icelandic low and Azores high }\end{array}$ & Mar/3 months \\
\hline El Niño Modoki index (EMI) & $\begin{array}{l}\text { SSTA: }\left(10^{\circ} \mathrm{S}-10^{\circ} \mathrm{N}, 165^{\circ} \mathrm{E}-140^{\circ} \mathrm{W}\right)-0.5 \times \\
\quad\left(15^{\circ} \mathrm{S}-5^{\circ} \mathrm{N}, 110^{\circ}-70^{\circ} \mathrm{W}\right)-0.5 \times \\
\quad\left(10^{\circ} \mathrm{S}-20^{\circ} \mathrm{N}, 125^{\circ}-145^{\circ} \mathrm{E}\right)\end{array}$ & Mar/3 months \\
\hline Antarctic Oscillation (AAO) & $\begin{array}{l}\text { The leading EOF mode of } 850 \text { or } 700 \mathrm{hPa} \\
\text { height anomalies south of } 20^{\circ} \mathrm{S}\end{array}$ & Apr-May/2 months \\
\hline Arctic Oscillation (AO) & $\begin{array}{l}\text { The leading EOF mode of the monthly } \\
\text { mean MSLP anomalies poleward } \\
\text { of } 20^{\circ} \mathrm{N}\end{array}$ & May/1 month \\
\hline
\end{tabular}

2009), Arctic Oscillation (AO; e.g., Gong and Ho 2003), El Niño Modoki index (EMI; e.g., Feng et al. 2011), dipole mode index (DMI; e.g., Saji et al. 1999; Xiao et al. 2015), North Atlantic Oscillation (NAO; e.g., Wu et al. 2009), and Niño-3.4 (Wang et al. 2000). Here we select the six climate indices (i.e., AAO, AO, EMI, DMI, NAO, Niño-3.4; listed in Table 2) associated with SSSa to train the RFRA. The RFRA experiments are performed in three steps. First, we quantify the importance of the seven indices by changing an individual index on the premise that the other factors remain constant. Second, we choose half the summer rainfall data randomly and associated indices to train the predictive model, and we input the remaining indices into the model to predict rainfall. Finally, we compare the predicted rainfall with another half of the observation data to evaluate the predictive value of all seven indices according to the coefficient of determination (Breiman 2001):

$$
R^{2}=1-\frac{V_{\text {residual }}}{V_{\text {total }}}
$$

where $R^{2}$ is the part of the variance that the predictive model can explain. Thus, the sum of variance that cannot be explained by the predictive model is given as

$$
V_{\text {residual }}=\sum_{k=1}^{n}\left[f(X)_{k}-P_{k}\right]^{2},
$$

where $f(X)$ is the predictive value from RFRA model, $P_{k}$ is the observed EAMR summer precipitation, $k=1, \ldots, n$ represents each of the studied year, and $n$ is the total number of studied years. The total variance of the observation data is given by

$$
V_{\text {total }}=\sum_{k=1}^{n}\left(P_{k}-\bar{P}\right)^{2}
$$

where $\bar{P}$ represents the overall average of the observed EAMR summer precipitation.

\section{Sustained ocean-terrestrial water cycle over the TNWP and the EAMR from spring to summer}

\section{a. Relationship between the spring SSS and the summer terrestrial rainfall}

First, we examine the spatial pattern and interannual variation of JJA rainfall over the EAMR. Figures 1a and $1 \mathrm{~b}$ show the first two leading modes from EOF analysis of JJA rainfall during 1980-2017, respectively. The first mode (EOF1) accounts for $21.2 \%$ of the total variance of the interannual variation of summer rainfall (Fig. 1a). The spatial pattern of EOF1 is characterized by a meridional triple-band pattern, that is, the significant positive anomaly is located over the middle part of the EAMR (central China, South Korea, and western Japan) and is sandwiched between negative anomalies over northern and southern China. The positive anomaly precipitation belt along the middle part of the EAMR is also called the mei-yu (baiu) rainband (Huang and Sun 1992; Wang and LinHo 2002). 


\section{(a) EOF1 21.2\%}

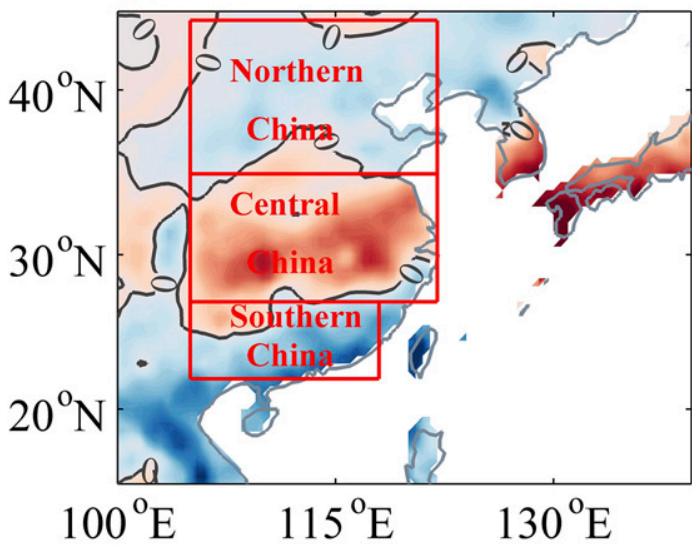

(b) EOF2 12.6\%

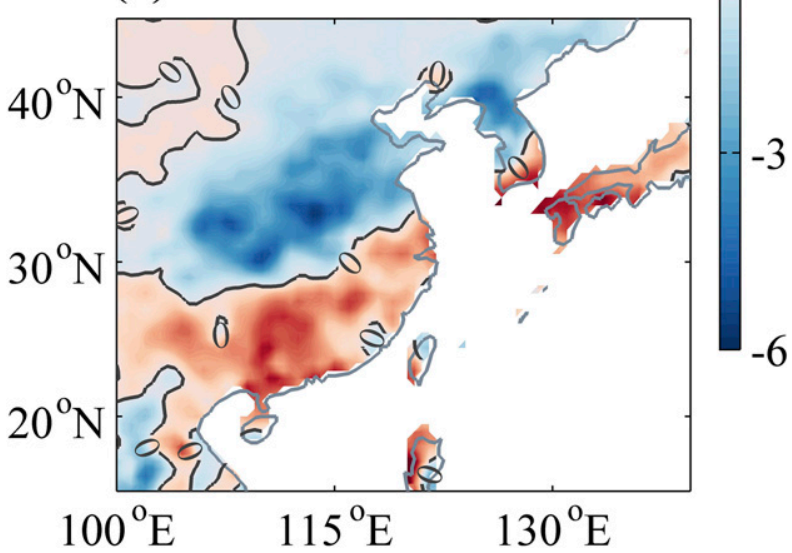

FIG. 1. The distribution of the (a) first and (b) second leading mode of EOF analysis of interannual variation of summer rainfall (June-August) in the East Asian monsoon region (EAMR) during 1980-2017, and the red boxes represent southern China, central China, and northern China, respectively.

In contrast to EOF1, the second mode (EOF2) accounts for $12.6 \%$ of the total variance of the interannual variation of JJA rainfall (Fig. 1b). This mode is characterized by a south-north dipole pattern, with a positive rainfall anomaly located south of the Yangtze River and a negative rainfall anomaly north of the Yangtze River. These two major patterns (EOF1 and EOF2) are consistent with many previous studies (e.g., Zhou and Yu 2005; Ye and Lu 2012). Because EOF1 accounts for much more of the variance than EOF2, we focus on EOF1 in the following analysis and briefly discuss EOF2 in the final section.

We further analyze the spring SSS in the oceans adjacent to the EAMR and its relation with the EAMR rainfall. Figure 2a shows that the low salinity can be found in the estuarine regions of Asia continent, especially in the Bay of Bengal and the East China Sea. The high salinity mainly appears in the Pacific Ocean and equatorial
Indian Ocean where evaporation exceeds precipitation. The temporal variations of SSSa and the EOF1 time series of EAMR rainfall exhibit a positive correlation over the TNWP, where the correlation coefficient ranges from 0.4 to 0.6 and is above the $95 \%$ confidence level (dots in Fig. 2a). Such a relationship suggests a link between the springtime SSS in the TNWP and the EAMR summer rainfall at interannual time scales.

Figure $2 \mathrm{~b}$ shows the interannual variations of JJA rainfall as represented by the normalized time series of EOF1 (herein, the rainfall index) and the normalized MAM SSSa averaged over the key ocean region (herein, the SSS index). The rainfall index is high in 1993, 1998, 2003, and 2015 when the JJA rainfall was excessive in central China (Wang et al. 2008; G. Chen et al. 2017). This large interannual variation of rainfall index is highly correlated with the normalized time series of SSS index, with a correlation coefficient of 0.44 . In the following analysis, the composite analysis is applied to the high $(1983,1992,1993,1998,2003,2010,2015$, and 2016) and low (1981, 1989, 1997, 2001, 2008, 2009, 2011, and 2012) years with the SSSa exceeding $40 \%$ of one standard deviation (see Fig. 2b). Because the SSSa reflects the evaporation-precipitation difference, we then examine the physical processes that connect the MAM SSSa to the regional water cycle. Moreover, the lead-lag relation between the MAM SSSa and the JJA rainfall indicates a predictive value on the monsoon rainfall over the EAMR, which warrants further analysis.

\section{b. Water vapor transport associated with the SSSa variations in the TNWP in spring}

To clarify the physical connection between oceanic SSS and terrestrial rainfall, we investigate the water vapor transport from the TNWP to the EAMR. In spring, the western Pacific subtropical high (WPSH) exhibits a southwestward extension over the South China Sea before the onset of summer monsoon (Fig. 3a). With the easterly wind (trade wind) at the southern flank of WPSH, the water vapor is transported westward from the TNWP to the South China Sea and Indochina regions. Much of the water vapor then moves northeastward on the western edge of the WPSH at $\sim 100^{\circ} \mathrm{E}$, and subsequently reaches southern China. Another pathway of water vapor transport is seen along $\sim 25^{\circ} \mathrm{N}$ at the southern flank of the Tibetan Plateau. These two pathways merge over southern China and Indochina regions, bringing abundant water vapor. This strong convergence of water vapor flux over the EAMR manifests a strong connection between the water vapor from the TNWP and the EAMR water cycle.

Figure $3 \mathrm{~b}$ shows the composite anomalies of the water vapor transport during the high-SSSa years. In these 
(a) Spring SSS
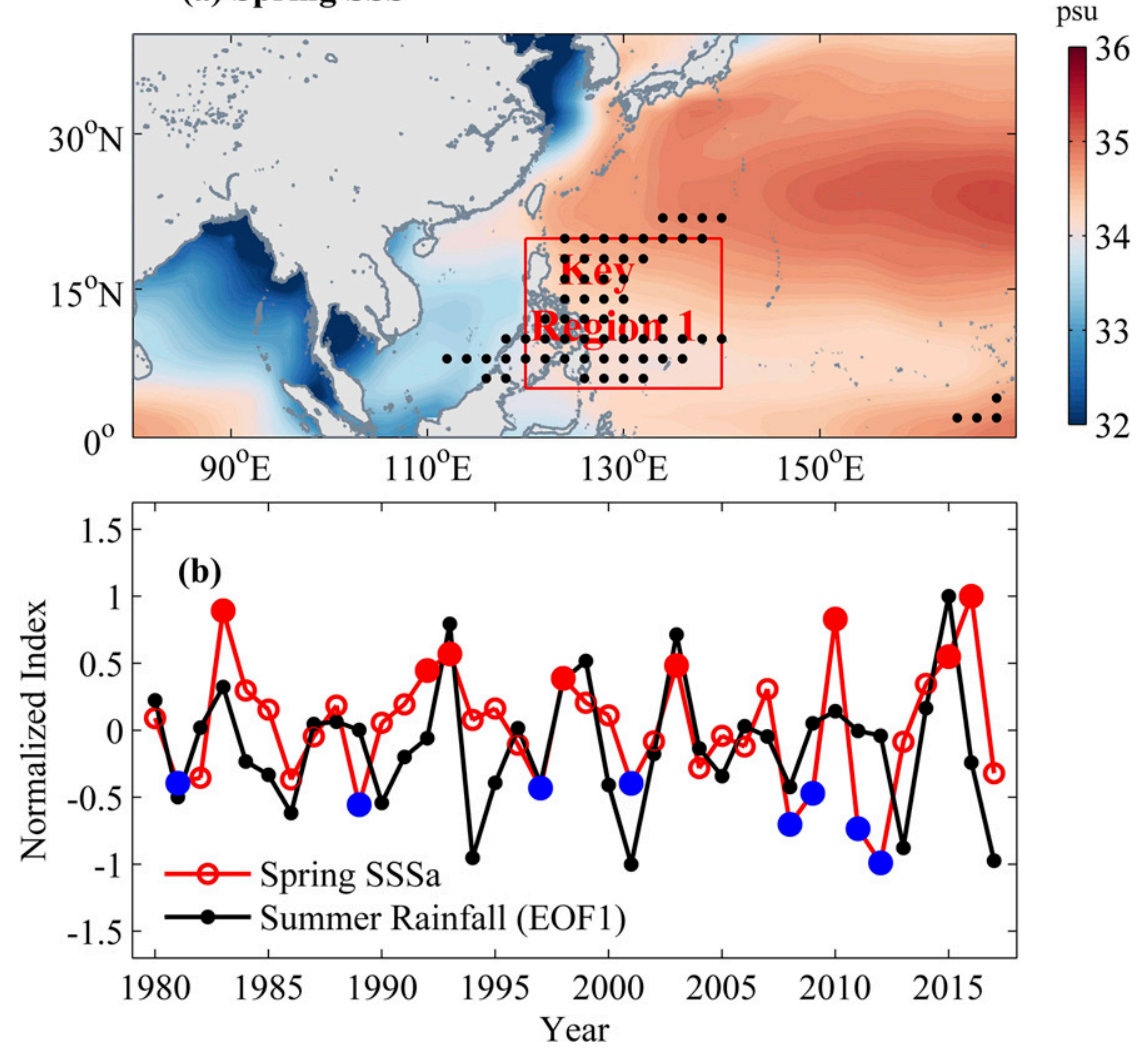

FIG. 2. (a) The spring mean sea surface salinity (SSS) in the ocean adjacent to the EAMR (color shading; units: psu), black dots represent the correlation coefficient between the EOF1 and the SSSa exceeding the $95 \%$ confidence level, and the red box represents the key region 1 $\left(5^{\circ}-20^{\circ} \mathrm{N}, 120^{\circ}-140^{\circ} \mathrm{E}\right)$ of SSSa over the tropical northwest Pacific, and (b) the normalized principal component corresponding to the first leading mode over the EAMR (black line with dots) and the springtime SSSa (March-May) averaged over the key region 1 (red line with dots), the red and blue solid dots represent the selected high- and low-SSSa years exceeding $40 \%$ of its standard deviation, respectively.

years, the source of anomalous water vapor is mainly from the TNWP and the South China Sea, while the westerly wind at the southern side of the Tibet Plateau has less influence. There is no obvious difference in the midlatitudes in spring. The positive anomalies (enhanced divergence) of water vapor flux divergence are mainly seen over the TNWP and the South China Sea, whereas the negative values (enhanced convergence) are seen in the EAMR (Fig. 3b). Such a dipole structure of water vapor flux divergence confirms the important role of the TNWP in regulating the EAMR water cycle.

Figure $3 \mathrm{c}$ shows the spatial pattern of water vapor transport and divergence in the low-SSSa years, which is nearly opposite to that in the high-SSSa years. The anomalous water vapor transport exhibits a cyclonic distribution over the EAMR. It leads to a suppressed water vapor flux from the TNWP compared to the climatological mean. The decreased wind speed also weakens the evaporation near the Philippine Sea and the South China Sea (Wang et al. 2000). As a result, the anomalous convergence of water vapor flux occurs in the TNWP and the South China Sea with $-0.2 \times$ $10^{-4} \mathrm{~kg} \mathrm{~m}^{-1} \mathrm{~s}^{-1}$ on average. The anomalous divergence of water vapor flux instead appears in the EAMR at a regional mean of $0.15 \times 10^{-4} \mathrm{~kg} \mathrm{~m}^{-1} \mathrm{~s}^{-1}$, leading to a weakened precipitation over the EAMR.

Both the climatological mean and anomalies of water vapor transport suggest that the TNWP provides the key source of water vapor for the EAMR in spring. This outflow area of water vapor corresponds well to the area of maximum salinity-rainfall correlation as shown in Fig. 2a. It suggests that the TNWP is also important for the interannual variability of water cycle over the EAMR. Former studies have shown that the Philippine Sea anomalous anticyclone is the key atmospheric circulation in affecting the water vapor transport and 
(a) Climatological Mean

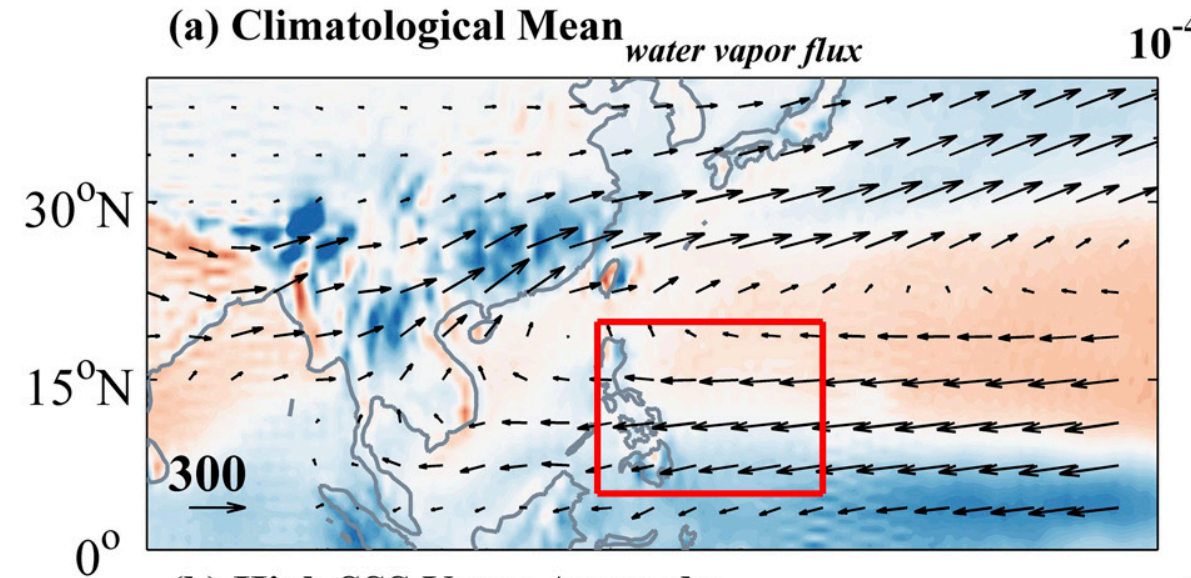

$10^{-4} \mathrm{~kg} /\left(\mathrm{m}^{2} \cdot \mathrm{s}\right)$

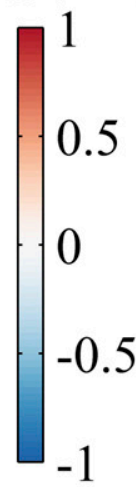

(b) High SSS Years Anomaly water vapor flux

$10^{-4} \mathrm{~kg} /\left(\mathrm{m}^{2} \cdot \mathrm{s}\right)$

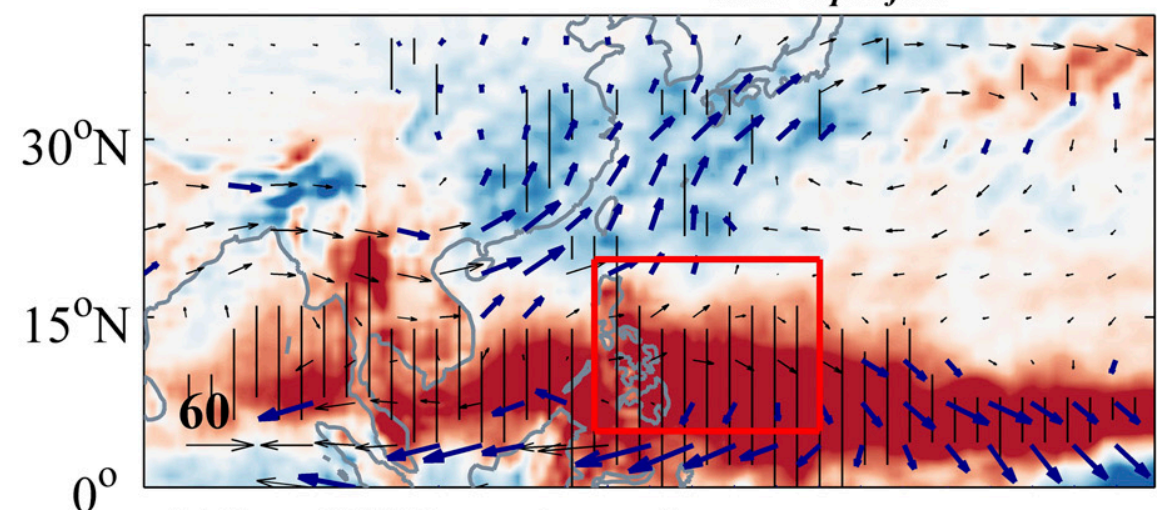

0.2

(c) Low SSS Years Anomaly

water vapor flux

$10^{-4} \mathrm{~kg} /\left(\mathrm{m}^{2} \cdot \mathrm{s}\right)$

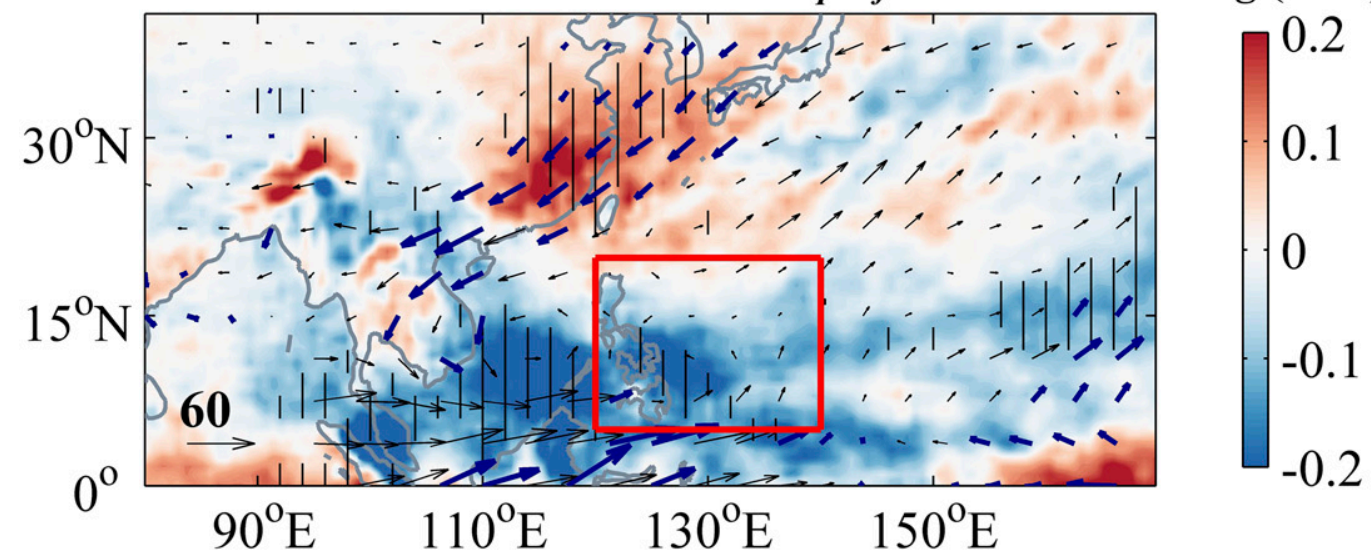

FIG. 3. (a) Springtime (March-May) climatology of the water vapor transport and the divergence of water vapor flux during 1980-2017, and the composite anomalies (March-May) of the water vapor transport and the divergence of water vapor flux around the peaks of (b) the eight high- and (c) the eight low-SSSa years illustrated in Fig. 2b. The shaded areas indicate the divergence/convergence (positive/negative values) of water vapor flux (color shading; units: $\mathrm{kg} \mathrm{m}^{-2} \mathrm{~s}^{-1}$ ), and the vectors indicate the water vapor transport (vectors; units: $\mathrm{kg} \mathrm{m}^{-1} \mathrm{~s}^{-1}$ ). The vertical lines in black and the vectors in blue represent the divergence (convergence) of water vapor flux and water vapor flux that are significant at the 0.1 level by Student's $t$ test, respectively. The red rectangle boxes represent the key ocean region of SSS index significantly associated with EOF1. 
precipitation over the EAMR during winter and spring (e.g., Wang et al. 2000). The Philippine Sea anomalous anticyclone not only can alter the local evaporation by changing wind speed but also can greatly influence the water vapor transport from tropics to EAMR (Wang et al. 2000). The maximum divergence of water vapor flux associated with the anticyclone is located near the TNWP where large SSSa is observed. Moreover, Pan et al. (2017) have revealed that the TNWP is the dominant oceanic moisture source region for the rainfall over the EAMR during spring by tracking tracers in atmospheric model. These results thus support the existence of physical connection between the SSS in the TNWP and the rainfall over the EAMR proposed in this study.

\section{c. Synchronous response of spring rainfall and soil moisture to the water vapor transport}

With the change of water vapor transport, how the surface variables such as soil moisture over the EAMR respond to the anomalous circulation and associated rainfall still remains a question. In this section, we examine first the spatial distribution of soil moisture over the EAMR and then the interannual variation of soil moisture and its relation with water vapor flux convergence and rainfall amount.

Figure 4a shows the climatological mean of spring soil moisture over the EAMR. Soil moisture content is high at southeastern China, the Korean Peninsula, and Japan, whereas it is relatively low over northern China. Such a spatial distribution of MAM soil moisture agrees well with the convergence of water vapor flux (Fig. 3a). It indicates that the soil moisture is tightly connected with the water cycle over the EAMR. Figure $4 b$ shows that the soil moisture exhibits positive anomalies in the highSSSa years over most of the EAMR, especially in central and southern China. The maximum anomalies of soil moisture are mainly located in central China, where the increase can be up to $\sim 10 \%$ of the climatological mean. The spatial pattern is well collocated with that of water vapor flux convergence (cf. Figs. $4 \mathrm{~b}$ and $3 \mathrm{~b}$ ). It indicates that the soil moisture can be regulated by the northward transport and convergence of water vapor that are greatly enhanced in the high-SSSa years. Figure 4c shows the soil moisture anomalies are negative over the EAMR in the low-SSSa years, with the spatial pattern nearly opposite to that in high-SSSa years. The decrease of soil moisture over southeastern China, the Korean Peninsula, and Japan can be $\sim 10 \%$ of the climatological mean. This soil moisture deficit agrees well with the anomalous divergence of water vapor flux (cf. Figs. $4 \mathrm{c}$ and $3 \mathrm{c}$ ). Therefore, the spring soil moisture exhibits a close association with the change in regional water cycle: The higher (lower) the SSSa in the TNWP
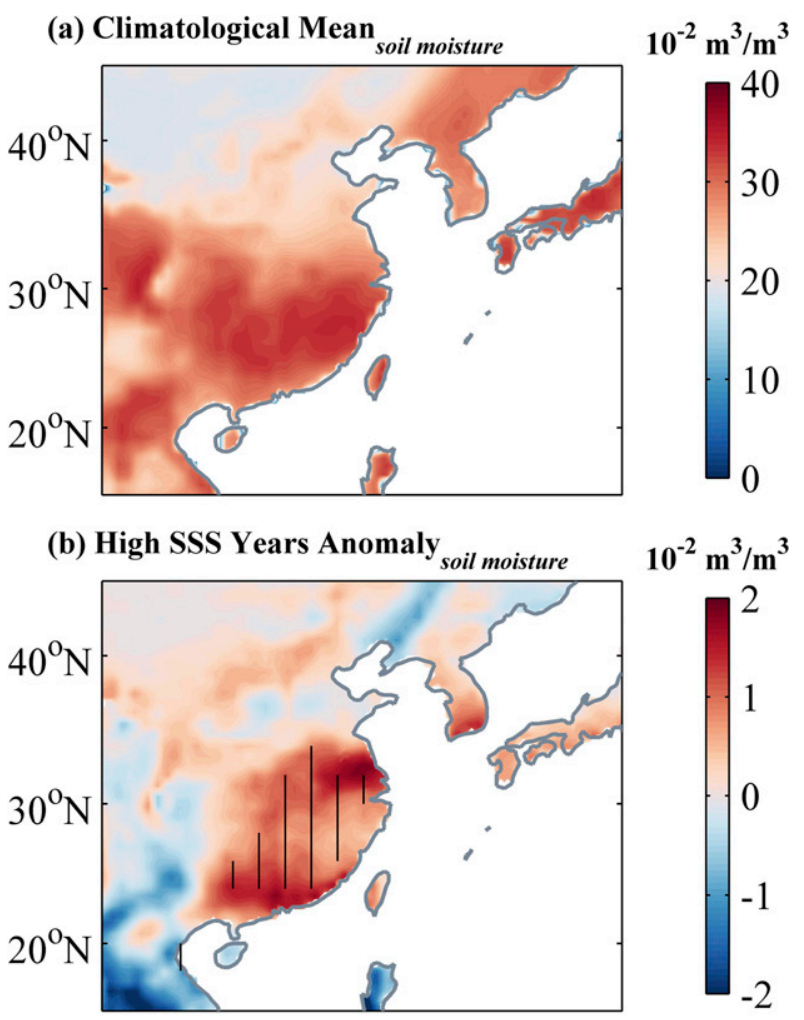

(c) Low SSS Years Anomaly

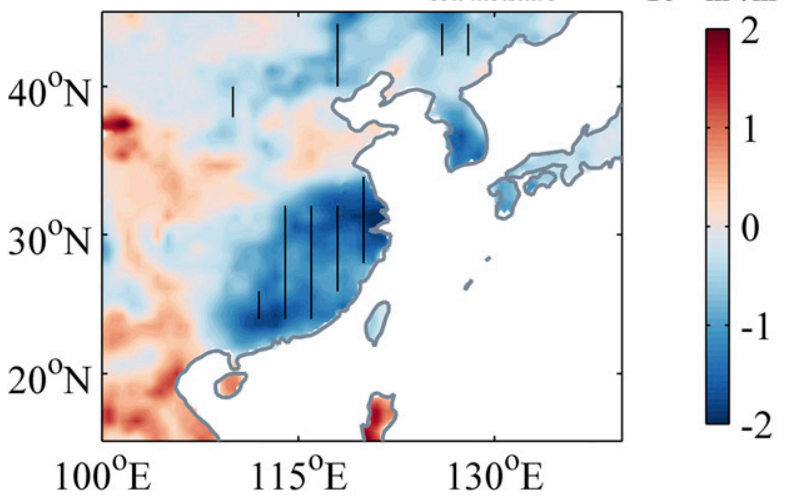

FIG. 4. (a) Springtime (March-May) climatology of the soil moisture during 1980-2017, and the composite mean (March-May) of soil moisture anomalies around the peaks of (b) the eight highand (c) the eight low-SSSa years illustrated in Fig. 2b. The shaded areas indicate the soil moisture content (color shading; units: $\mathrm{m}^{3} \mathrm{~m}^{-3}$ ). The vertical lines in black represent the soil moisture anomalies that are significant at the 0.1 level by Student's $t$ test, respectively.

is, the stronger (weaker) the ocean-to-land transport of water vapor is, and the wetter (drier) soil moisture content over the EAMR becomes.

Besides the spatial patterns, the interannual variation of soil moisture over the EAMR also responds to the concurrent water vapor transport and rainfall. Figure 5a 

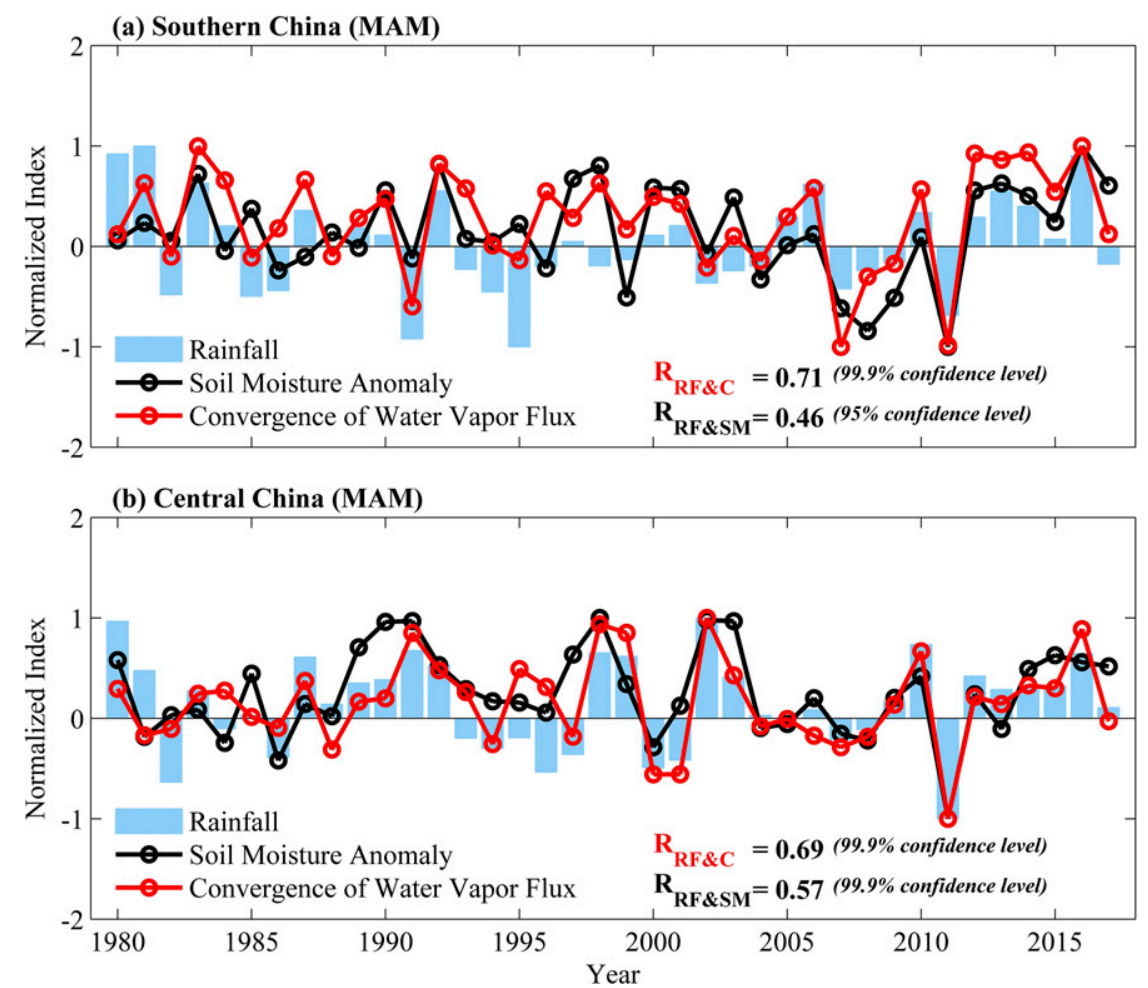

FIG. 5. The normalized time series of the spring rainfall, the convergence of water vapor flux, and the soil moisture anomaly (March-May) of (a) southern China and (b) central China during 1980-2017, the $R_{\mathrm{RF} \& \mathrm{C}}$ represents the correlation between the convergence of water vapor flux and the rainfall, and the $R_{\mathrm{RF} \& \mathrm{SM}}$ represents the correlation between the rainfall and the soil moisture anomaly.

shows that over southern China the spring rainfall increases simultaneously with the enhanced convergence of the water vapor flux. Their correlation coefficient is as high as 0.71 , above the $99.9 \%$ confidence level. The correlation coefficient between the spring rainfall and soil moisture also reaches 0.46 , above the $95 \%$ confidence level. Similar relationships among soil moisture, rainfall and water vapor flux convergence exist in central China as well (Fig. 5b). The interannual variations of these three variables are similar in central and southern China, indicating a consistent large-scale feature. These results suggest that both the spatial distribution and interannual variation of spring soil moisture and rainfall over the EAMR are strongly regulated by the convergence of water vapor flux from the TNWP.

\section{d. Sustained pattern of large-scale anomalous water vapor transport in summer}

The anomalous water vapor transport from tropics to EAMR in summer is further illustrated by the JJA anomalies of 850-hPa geopotential height and columnintegrated water vapor flux (Fig. 6). Figure 6a shows an anomalous high governs southern China and the South
China Sea in the high-SSSa years compared to the climatological mean. The water vapor fluxes exhibit an anomalously anticyclonic pattern over southern China with an enhanced water vapor transport from tropics to central China. The water vapor fluxes converge and bring more rainfall in central China than in southern/ northern China. Figure $6 \mathrm{~b}$ shows that the anomalies of atmospheric circulation and water vapor fluxes in the low-SSSa years are nearly opposite to those in the highSSSa years, resulting in the suppressed rainfall over central China. Therefore, the anomalous pattern of water vapor transport from tropics is sustained in summer and regulates the EAMR rainfall with corresponding changes of water vapor flux. Former studies have revealed that the sustained anomalous water vapor transport is anchored by the Philippine Sea anomalous anticyclone in summer, which is related to the air-sea interaction in the Indo-Pacific Ocean (Wang et al. 2000; Xie et al. 2009, 2016). Under the external forcing of large-scale atmospheric circulation, the anomalous water vapor transport not only exists in spring but also lasts through summer, thereby producing continuous rainfall over the EAMR. 


\section{(a) High SSS Years Anomaly}

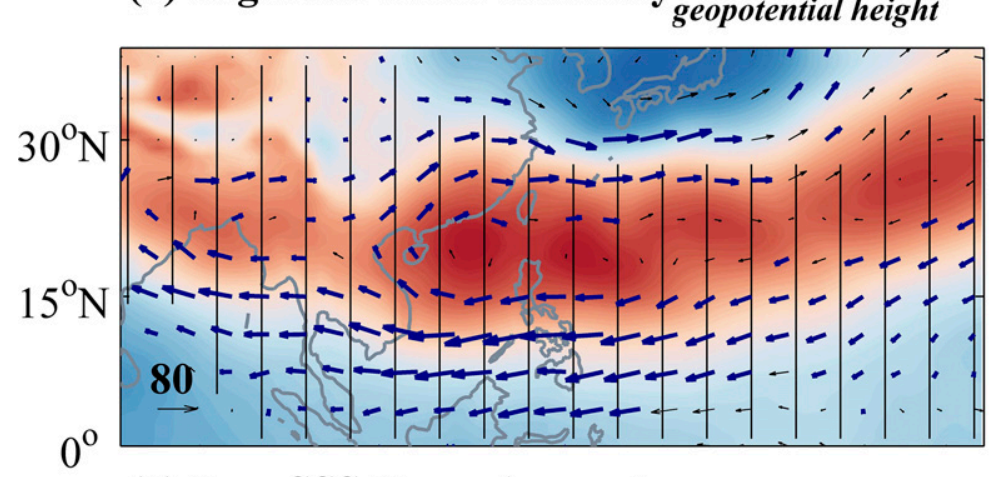

(b) Low SSS Years Anomaly

gpm

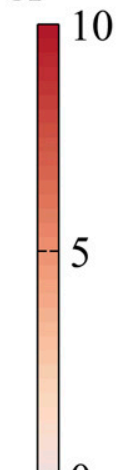

0

$-5$

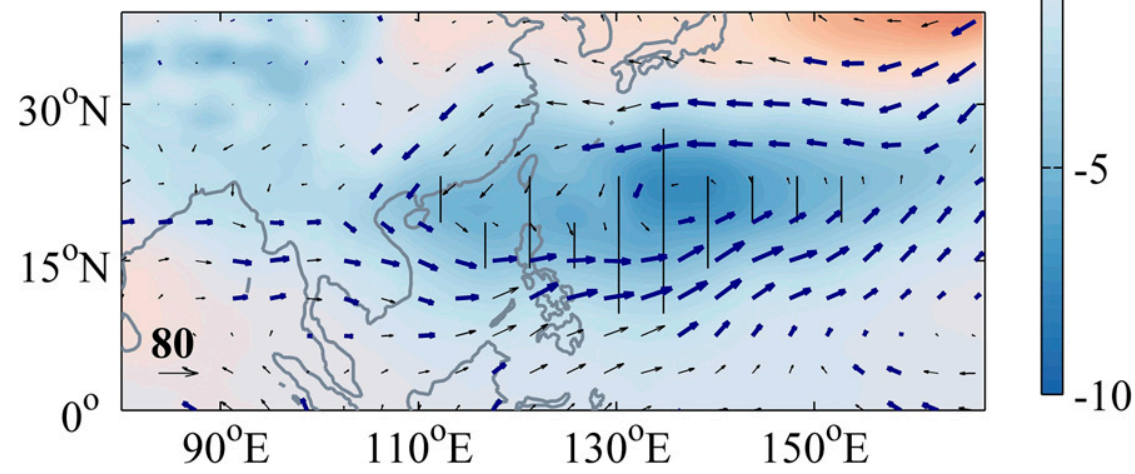

FIG. 6. The composite anomalies (June-August) of the geopotential height at $850 \mathrm{hPa}$ (color shading; units: gpm) and vertically integrated $(1000-100 \mathrm{hPa})$ water vapor flux transport (vectors; units: $\mathrm{kg} \mathrm{m}^{-1} \mathrm{~s}^{-1}$ ) around the peaks of (a) the eight high- and (b) the eight low-SSSa years illustrated in Fig. 2b. The vertical lines in black and the vectors in blue represent the anomalies of the geopotential height and water vapor flux that are significant at the 0.1 level by Student's $t$ test, respectively.

\section{Effects of the spring soil moisture on the EAMR summer rainfall}

Soil moisture as a key component of the land surfaces can affect evaporation and surface energy fluxes, and it can further modify surface thermal conditions and precipitation systems (Koster et al. 2004; Xue et al. 2004). Given that East Asia is an active land-atmosphere coupling area (Zhang et al. 2011), the roles the soil moisture plays in extending the effect of ocean-to-land water cycle in spring (signaled by the SSSa) to the regional summer rainfall need to be examined and validated.

\section{a. Effect of the spring soil moisture on surface thermal conditions via surface energy fluxes}

First, the soil moisture can affect the partitioning of the sensible and latent heat flux through evaporation (Kim and Hong 2007). To depict the effect of spring soil moisture, we make composite analysis of the anomalies of surface variables. Figures $7 \mathrm{a}-\mathrm{d}$ show the difference of surface sensible heat flux, surface latent heat flux, near-surface specific humidity, and 2-m air temperature in May between the high- and low-SSSa years. In the high-SSSa years, an evident decrease of the surface sensible heat flux occurs over most of the EAMR, especially in central and northern China with the largest decrease up to $20 \mathrm{~W} \mathrm{~m}^{-2}$ (Fig. 7a), while the latent heat flux is relatively large in central China (Fig. 7b). This suggests that the wetter (drier) soil moisture can lead to a smaller (larger) Bowen ratio (sensible heat flux/ latent heat flux) in central China because of higher (lower) evaporation (as suggested by Kim and Hong 2007). The latter can be confirmed by the positive anomalies of specific humidity (Fig. 7c) and lower air temperatures in central China (Fig. 7d). We thus conclude that anomalously spring soil moisture can exert a significant effect on the concurrent surface energy fluxes.

Second, the soil moisture anomalies over the EAMR can alter surface thermal conditions to modify the development of regional atmospheric circulation in summer (Kim and Hong 2007). To depict the change in regional atmospheric circulation, we use the intensity 
(a) Sensible Heat

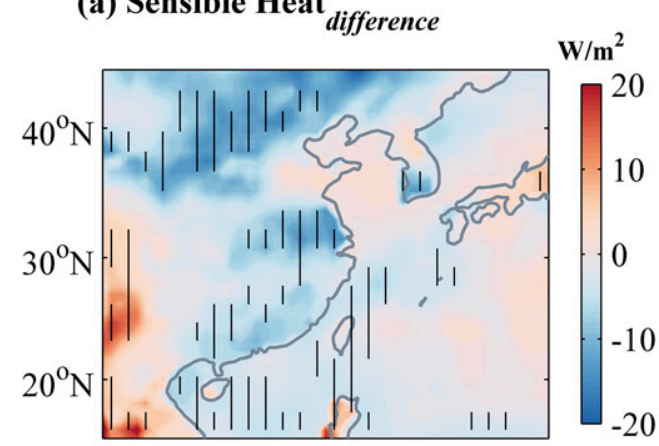

(c)Near Surface Specific Humidity

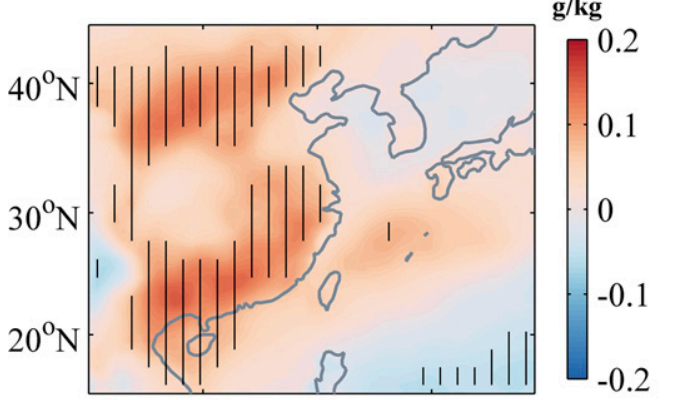

$100^{\circ} \mathrm{E} \quad 110^{\circ} \mathrm{E} \quad 120^{\circ} \mathrm{E} \quad 130^{\circ} \mathrm{E}$ (b) Latent Heat

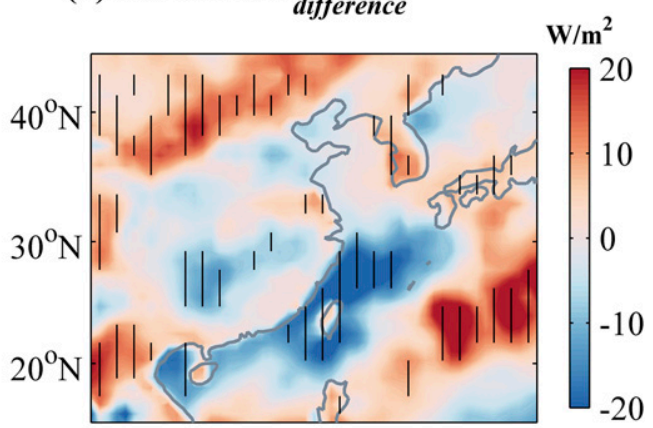

(d) $2 \mathrm{~m}$ Air Temperature

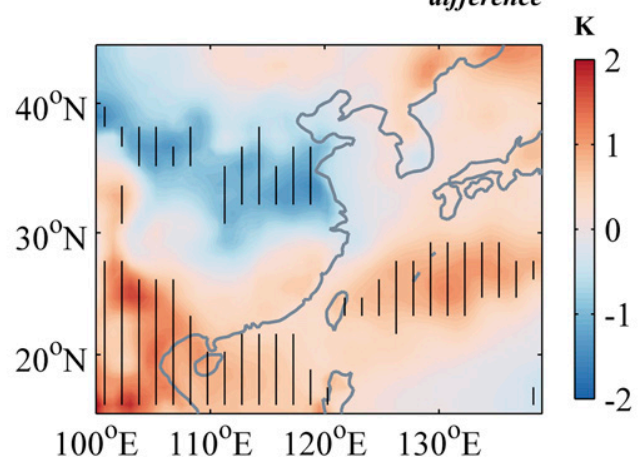

FIG. 7. Difference in (a) surface sensible heat flux (units: $\mathrm{W} \mathrm{m}^{-2}$ ), (b) surface latent heat flux (units: $\mathrm{W} \mathrm{m}^{-2}$ ), (c) near-surface specific humidity (units: $\mathrm{g} \mathrm{kg}^{-1}$ ), and (d) 2-m air temperature (units: $\mathrm{K}$ ) in May between the peaks of the eight high- and the eight low-SSSa years. Positive (negative) values correspond to decreases (increases) from the high-SSSa years to the low-SSSa years. The vertical lines in black represent the anomalies of surface energy fluxes that are significant at the 0.1 level by Student's $t$ test, respectively.

index of the East Asian summer monsoon. Wang et al. (2008) proposed the first principal component of summer precipitation and circulation in the East Asian domain $\left(0^{\circ}-50^{\circ} \mathrm{N}, 100^{\circ}-140^{\circ} \mathrm{E}\right)$ as the intensity index, which can explain a large part of the interannual variance of summer rainfall. A high value of the index corresponds to the abundant mei-yu (baiu) rainfall with suppressed northward extension of southwesterly monsoon flow that mainly affects the southern regions. The EOF1 rainfall index of this study in a slightly smaller domain $\left(15^{\circ}-45^{\circ} \mathrm{N}, 100^{\circ}-140^{\circ} \mathrm{E}\right)$ is very similar to Wang's index, with the correlation coefficient greater than 0.7 and exceeding the $99.9 \%$ confidence level. Thus, here we use the EOF1 rainfall index (black line with dots in Fig. 2b) to represent the intensity of East Asian summer monsoon.

The wetter (drier) soil moisture in central China in May is accompanied by decreased (enhanced) oceanland thermal contrast, which agrees well with the distribution of anomalous temperature in Fig. 7 d. Figure 8 also shows that the soil moisture anomaly is negatively correlated with the land-sea thermal contrast with a correlation coefficient $(-0.67)$ above the $99.9 \%$ confidence level. Besides, the soil moisture anomaly is correlated with the monsoon index (i.e., the summer rainfall index), with a coefficient correlation $(+0.42)$ above the $95 \%$ confidence level. The relationship among these three indices confirms that the lower air temperature in central China due to a wet soil in late spring can lead to the weak land-sea thermal gradient, which modifies regional atmospheric circulation in the following summer, thereby helping to amplify the summer rainfall over central China.

\section{b. Effect of the spring soil moisture on precipitation activity}

The soil moisture in the EAMR also plays a role in the local soil moisture (LSM)-precipitation $(P)$ feedback during the progress of summer monsoon. Some studies have shown that the LSM- $P$ feedback may be positive or negative in different regions (e.g., Schar et al. 1999; Zhong et al. 2018). The regional dependence indicates that different conditions of summer soil moisture can lead to different rainfall. Here, we further examine the 


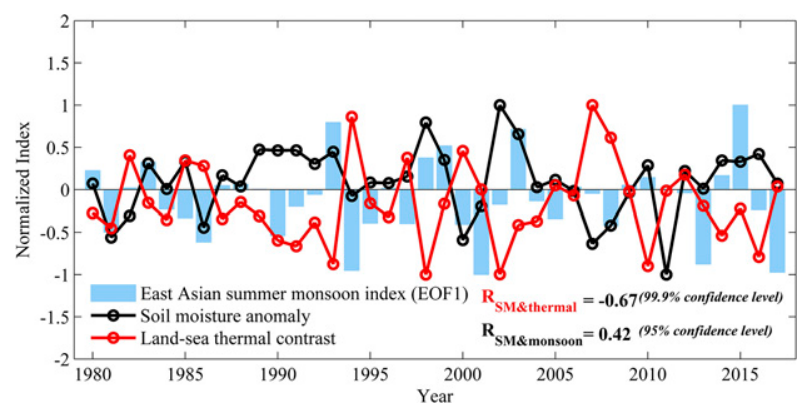

FIG. 8. The time series of the interannual variation of the East Asian summer monsoon index (EOF1, blue bars), the soil moisture anomalies in central China (black line with dots), and the land-sea thermal contrast between the southeastern China $\left(22^{\circ}-35^{\circ} \mathrm{N}, 105^{\circ}-120^{\circ} \mathrm{E}\right)$ and the South China Sea $\left(5^{\circ}-21^{\circ} \mathrm{N}, 105^{\circ}-120^{\circ} \mathrm{E}\right)$ in May (red line with dots).

LSM- $P$ feedback over the EAMR to clarify the SSSrainfall link. We first use the autocorrelation method to measure the seasonal memory of soil moisture. Then we estimate the LSM- $P$ feedback process through linking atmospheric conditions and precipitation properties.
Figure 9a shows that the MAM and JJA anomalies of soil moisture have a positive correlation coefficient above 0.4 (95\% confidence level) in central China. It indicates that part of the soil moisture signal can be preserved from spring to summer. In the following analysis, we use the JJA soil moisture in central China to investigate the LSM- $P$ feedback mechanism.

We examine the precipitation characteristics in central China with emphasis on stratiform and convective precipitation. Previous studies have found that the precipitation over the EAMR is mainly contributed by stratiform and convective precipitation that can account for nearly $95 \%$ of the total precipitation in the EAMR (Fu and Liu 2003). The two precipitation types have different rain rate, rain fraction and vertical structures because of the differences in microphysics and thermodynamic processes during their formation (Liu et al. 2013). Figure $9 b$ shows the seasonal change of stratiform and convective precipitation, and the soil moisture content in central China during 1998-2014. Stratiform (a) Soil Moisture Correlation

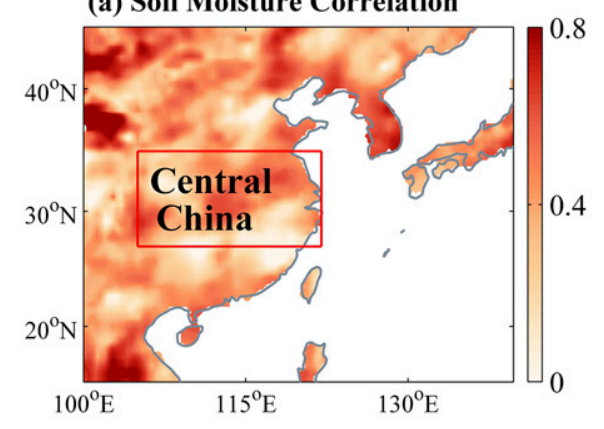

(b) Seasonal Variations in Central China

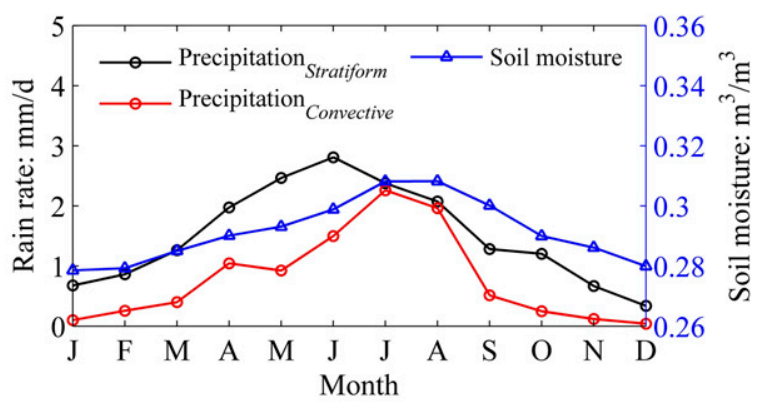

(c) Interannual Variations in Central China

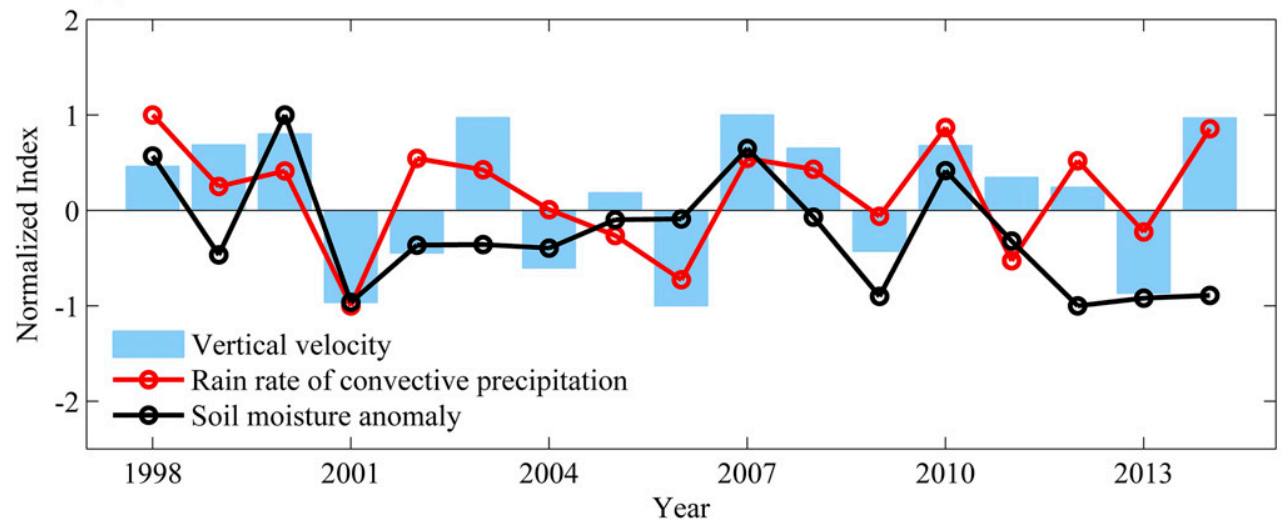

FIG. 9. (a) The distribution of the autocorrelation coefficients between the spring and summer soil moisture in the EAMR, and the red box represents central China, (b) the seasonal variation of stratiform (black line with dots) and convective precipitation (red line with dots) rain rate, and the soil moisture (blue line with triangles) in central China during 1998-2014, and (c) the normalized time series of interannual variation of vertical velocity in $500 \mathrm{hPa}$ (blue bars), the convective precipitation rain rate (red line with dots), and the soil moisture anomaly (black line with dots) in summertime (all are June-August) during 1998-2014. 
precipitation is the major form throughout the year, and reaches the highest rain rate of $2.8 \mathrm{~mm} \mathrm{day}^{-1}$ in June. Such phenomenon is related to the variations of largescale circulation, especially the seasonal advance of summer monsoon and the northward movement of monsoon rain belt (Fu and Liu 2003). Figure 9b also shows that convective precipitation grows rapidly in July-August and contributes an amount nearly equal to stratiform precipitation. It corresponds to the increasing mesoscale systems due to intense heating and convective instability in summer (Chen et al. 2014). The convective precipitation also exhibits a seasonal variation very similar to that of soil moisture content. These features indicate that convective precipitation can reflect the thermal and moist influence of underlying land surfaces on local water cycle.

We further analyze the variation of convective precipitation to clarify the LSM- $P$ feedback. Figure 9c shows the interannual variations of JJA soil moisture, vertical velocity, and convective precipitation in central China. The correlation coefficient between soil moisture and vertical velocity can reach 0.75 and exceeds the $99 \%$ confidence level. It suggests that the anomalously wet surface tends to increase the supply of water vapor into the atmosphere through evaporation. The resultant high moist static energy can subsequently induce the ascending motion in the troposphere. The enhanced vertical velocity can correspond to an increased rain rate of convective precipitation, with a correlation coefficient of 0.49 . This relation between soil moisture and convective precipitation thus suggests a positive LSM- $P$ feedback over central China in the summer, which is consistent with the most recent study (Zhong et al. 2018). Further analysis of TRMM data in 1998-2014 also shows that the convective precipitation amount increases more than $29 \%$ in three high-SSSa years (1998, 2003 , and 2010), while it decreases by $12 \%$ in five lowSSSa years $(2001,2008,2009,2011$, and 2012) compared to the climatological mean. Therefore, the increased soil moisture in central China favors the growth of local convective precipitation because of the positive LSM- $P$ feedback.

\section{Predictability of the EAMR rainfall using SSS data}

In previous sections, we reveal the physical mechanisms of SSS-rainfall link across seasons and regions. The envisioned SSS-rainfall link involves the coupled ocean-atmosphere-land process with a multifacet evolution. The evolution can be traced back to the largescale ocean-to-land water vapor transport, which is signaled in advance by the spring SSS. In this respect, the

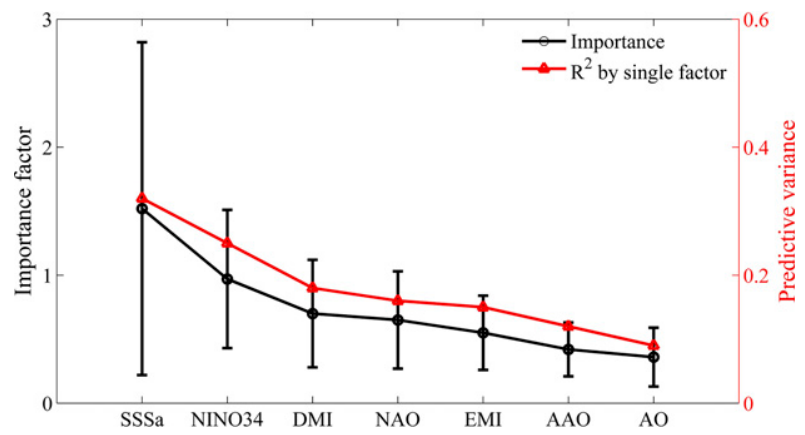

FIG. 10. The ranking of the importance of seven indices in the random forest prediction model (RFRA, black line with dots), and the predictive variance explained by each single indices (red line with triangles).

spring SSS in the TNWP is thus expected to provide a predictive value to the JJA rainfall over the EAMR.

More than the SSS, many studies have pointed out that a series of well-known climate modes, such as ENSO, AAO, and NAO can modulate the EAMR summer rainfall through large-scale atmospheric circulations (e.g., Wang et al. 2000; Gong and Ho 2003; Xie et al. 2009). Here, we apply the RFRA as introduced in section $2 b$ to evaluate the importance of the spring SSS in the TNWP and other six climate indices (Table 2) for the prediction of summer rainfall over the EAMR. Before applying the RFRA, we use the correlation analysis to find the highest correlation time between six climate indices and EOF1 of the EAMR summer rainfall shown in Fig. 2b. The highest correlation and lead-lag time of these indices with rainfall are listed in Table 2. We then use the values of six climate indices at their highestcorrelation months together with the MAM SSS index as the input to the RFRA. The RFRA is run with 1000 iterations, and the regression results are averaged to obtain a predictive relationship and the relative importance associated with each of the seven indices.

Figure 10 shows that the SSS index has the highest importance in predicting the EAMR summer rainfall, with a factor of 1.52. The Niño-3.4 index has the second high score (0.97) and that of AO is lowest (0.36). Previous studies suggested that the SSS in the TNWP can be partly influenced by the ENSO signal (Corbett et al. 2017). As shown in Fig. 10, the relative importance of the SSS in the TNWP is larger than that of Niño-3.4 index, suggesting that the SSS signal can offer additional predictive value for the EAMR summer rainfall from ENSO. To further estimate the predictive value of individual indices, we input the indices separately to the RFRA. Based on Eqs. (1)-(3) in section 2b, the predicted rainfall by the SSS in the TNWP can explain $32 \%$ of the variance of observed rainfall, which is highest 
among all seven indices (Fig. 10). The ranking of seven indices in terms of the variance is consistent with that of importance factor.

We then input all seven indices together to the averaged predictive relationship from the RFRA. Figure 11 shows that the predicted rainfall by all seven indices can explain $40 \%$ of the total variance of observed rainfall, while the prediction with six indices excluding the SSS index only accounts for $24 \%$. The correlation coefficient of the predicted and observed rainfall in the group with SSS index is much higher than that without SSS index. In particular, for the years that are anomalously wet (1993, 2003, and 2015) or dry (1986, 1994, 2001, 2013, and 2017), the prediction is much improved using the indices with the SSS index compared to that without the SSS index (Fig. 11). Therefore, incorporating the spring SSS signal into the predictive model can greatly improve the prediction skill of the EAMR summer rainfall especially for the extreme events.

\section{Conclusions and discussion}

In this paper, we have investigated the relationship between the spring SSSa in the TNWP and the summer rainfall of the EAMR using a suite of observation and reanalysis data. The physical processes associated with this relationship are also illustrated in detail. We further use the RFRA to evaluate the SSS index for the predictive skill of summer rainfall. The major findings are summarized as follows:

1) The interannual variability of the spring SSS in the TNWP are highly correlated with the first leading mode of summer rainfall over the EAMR. This SSSrainfall link involves a multifacet evolution: the sustained water vapor transport from ocean to continent in spring-summer and the induced response feedback of soil moisture on land. On the one hand, the anomalous anticyclonic (cyclonic) circulation over the TNWP can enhance (suppress) evaporation and water vapor transport from ocean to land in spring, which is clearly denoted by the high (low) SSS. Water vapor flux from the TNWP strengthens and converges to the EAMR to produce the spring rainfall and increase the local soil moisture in the EAMR. Thus, the spring soil moisture there exhibits a simultaneous response to the change in the regional water cycle. This ocean-to-land water vapor transport is sustained in summer and continues to affect the EAMR water cycle because of the persistence of Philippine Sea anomalous anticyclone. The higher the SSS in the TNWP is, the stronger the ocean-toland transport of water vapor becomes, and the

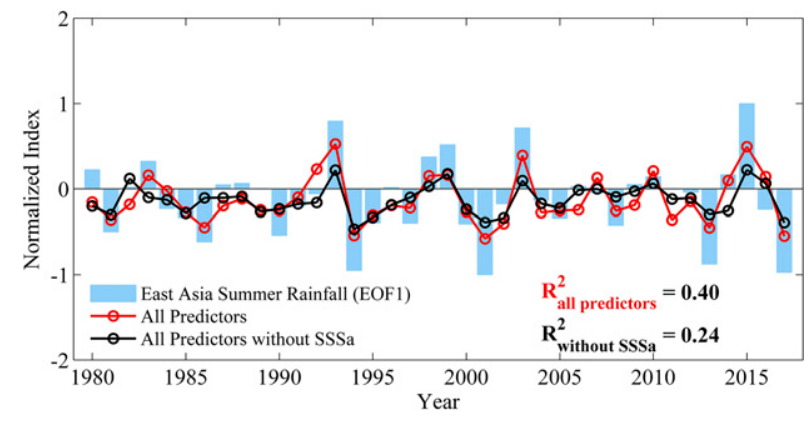

FIG. 11. The time series of the interannual variations of EOF1 of the EAMR summer rainfall (blue bars), the predicted precipitation anomalies by all predictors (red line with dots), and all predictors without SSSa (black line with dots).

wetter the soil moisture content over the EAMR reaches.

On the other hand, the sustained soil moisture over the EAMR helps to amplify the summer rainfall by modifying surface thermal conditions and precipitation systems over the EAMR. In the high-SSS years, the wet soil in spring is usually accompanied by a weak land-sea thermal gradient via surface energy fluxes over the EAMR. As a result, the local soil moisture in central China can alter surface thermal conditions to modify the regional atmospheric circulation in summer, which helps to amplify the rainfall over central China. Meanwhile, the increased soil moisture in central China also favors the growth of local convective precipitation because of the positive LSM- $P$ feedback. The multifacet evolution can be traced back to the large-scale ocean-to-land water vapor transport, which can be signaled in advance by the spring SSSa. Therefore, the spring SSSa in the TNWP can be used for an indicator of the ocean-terrestrial water cycle and a good precursor of the summer rainfall over EAMR.

2) By applying the RFRA, we show that including the spring SSSa of the TNWP can result in a higher predictive skill of summer rainfall. The SSS index is ranked as the most important predictor in the RFRA with a score of 1.52 , which is the highest among seven indices. The RFRA also shows that the SSS index can offer additional value for predicting the EAMR summer rainfall from ENSO, though the SSS in the TNWP can be partly influenced by the ENSO signal. The explained variance by the prediction in the group with the SSS index can be up to $40 \%$ of the observed rainfall, compared to $24 \%$ by that without the SSS index. In some extreme precipitation years, the gain by adding the SSS index to the group of predictors is more than the other six indices 

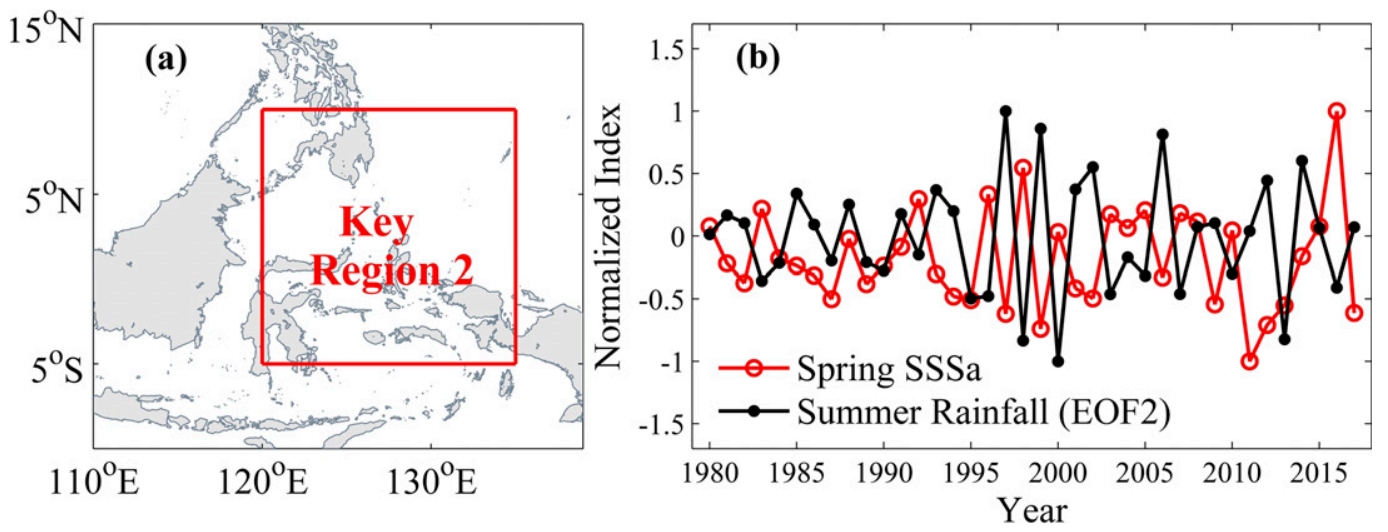

FIG. 12. (a) The red box represents the key region $2\left(5^{\circ} \mathrm{S}-10^{\circ} \mathrm{N}, 120^{\circ}-135^{\circ} \mathrm{E}\right)$ of SSSa over the tropical western Pacific, and (b) the normalized principal component corresponding to the second leading mode over the EAMR (black line with dots) and the springtime SSSa (March-May) averaged over the key region 2 (red line with dots).

combined. Thus, the spring SSS index in the TNWP, as a precursor, can be beneficial to the forecast of summer rainfall over the EAMR.

In this study, we show that the soil moisture over central China can extend the spring SSS signal to the following summer through its lasting effect on the regional water cycle. Similar SSS-rainfall linkages have been documented for the U.S. Midwest (Li et al. 2016a, 2018). Our work also demonstrates some interesting differences between the two regions. As the EAMR is closer to the ocean than the U.S. Midwest, the largescale atmospheric circulation responds to not only the soil moisture anomalies over the EAMR, but also the lasting signal of the Philippine Sea anticyclone (Wang et al. 2000; Xie et al. 2009; Chen et al. 2016). Moreover, soil moisture can directly change summer precipitation through regulating the local convective precipitation over the EAMR (Zhong et al. 2018). These features indicate the complexity of the water cycle over the EAMR (Webster and Yang 1992; Ding and Chan 2005). As we know, many previous studies suggested that soil moisture can modulate atmospheric conditions and rainfall systems aloft, indicating a local feedback of underlying surfaces over the EAMR (Kim and Hong 2007; Zuo and Zhang 2016). In this study, this process is included as a lasting effect of the ocean-to-land water cycle, which complements the water vapor transport by the large-scale anomalous atmospheric circulation as signaled by the spring SSSa. The proposed SSS-rainfall link thus allows us to bring in the signal of external forcing over the TNWP to combine with the local feedback of soil moisture on land and as a whole it can provide a more comprehensive representation of external forcing and ocean-land linkage. Besides, it was recognized that the observation of soil moisture has been challenging in the past (Xue et al. 2004), so adopting the SSSa in the seasonal forecast of rainfall over the EAMR is a viable approach.

Our conclusions of the SSS-rainfall link are based on the analysis of the first mode of the summer rainfall. Previous studies have pointed out that the EOF2 is another key feature of the precipitation pattern over the EAMR (Zhou and Yu 2005; Ye and Lu 2012). We also note that a negative correlation between EOF2 and SSSa can be found over the tropical western Pacific centered at $5^{\circ} \mathrm{S}-10^{\circ} \mathrm{N}, 120^{\circ}-135^{\circ} \mathrm{E}$ (the red box in Fig. 12a). The correlation coefficient ranges from -0.3 to -0.35 , which is above the $90 \%$ confidence level (Fig. 12b). Therefore, the tropical western Pacific appears as the key region for the first two EOF modes of summer rainfall over the EAMR (see Figs. 2a and 12a). The water vapor transport from the tropical western Pacific modulated by the Philippine Sea anticyclone plays an important role in the changes of water cycle over the EAMR in spring-summer (Zhou and Yu 2005; Wang et al. 2008; Z. Chen et al. 2017). Besides, the two key regions have a large portion of overlaying areas, suggesting the signal of the first key region also contains some values for predicting the EOF2 of summer rainfall over the EAMR, which deserves further studies in the future.

We also note that the EAMR summer rainfall can be attributed to both the concurrent summer evaporation and water vapor transport from adjacent oceans, which are not separated in this study as we focus on the predictive value of the preceding spring signal. The anomalous pattern of water vapor transport from tropics to EAMR not only exists in spring but also lasts through summer because of the sustained Philippine Sea anticyclone (Wang et al. 2000; Xie et al. 2009). The lasting 
atmospheric circulation in summer, although with a less predictive value, might be important to our understanding of the EAMR water cycle (Ding and Chan 2005; He et al. 2016). As the SSS variations are now being routinely monitored by satellite and the global Argo network, future investigations on such large-scale variables will advance our understanding of the air-sea interaction and hydrological cycle.

Acknowledgments. We thank the Met Office for providing EN4 data, CPC of NOAA and TRMM of NASA for precipitation data, and ERA-Interim for the reanalysis data (i.e., soil moisture, wind, geopotential, atmospheric boundary layer height, and the water vapor flux). This study was supported by the Strategic Priority Research Program of the Chinese Academy of Sciences (XDA10010304), the National Natural Science Foundation of China (41575068 and 41775085), and the Scientific and Technological Innovation Team Project of Guangzhou Joint Research Center of Atmospheric Sciences, China Meteorological Administration (Project 201703). We gratefully acknowledge the use of the HPCC at the South China Sea Institute of Oceanology, Chinese Academy of Sciences. We also thank two anonymous reviewers and Dr. Ray Schmitt for their helpful comments.

\section{REFERENCES}

Bingham, F. M., and T. Lee, 2017: Space and time scales of sea surface salinity and freshwater forcing variability in the global ocean $\left(60^{\circ} \mathrm{S}-60^{\circ} \mathrm{N}\right)$. J. Geophys. Res. Oceans, 122, 2909-2922, https://doi.org/10.1002/2016JC012216.

Breiman, L., 2001: Random forests. Mach. Learn., 45, 5-32, https:// doi.org/10.1023/A:1010933404324.

Chen, G., R. Yoshida, W. Sha, T. Iwasaki, and H. Qin, 2014: Convective instability associated with the eastwardpropagating rainfall episodes over eastern China during the warm season. J. Climate, 27, 2331-2339, https://doi.org/ 10.1175/JCLI-D-13-00443.1.

— W. Sha, T. Iwasaki, and Z. Wen, 2017: Diurnal cycle of a heavy rainfall corridor over East Asia. Mon. Wea. Rev., 145, 3365-3389, https://doi.org/10.1175/MWR-D-16-0423.1.

Chen, Z., Z. Wen, R. Wu, X. Lin, and J. Wang, 2016: Relative importance of tropical SST anomalies in maintaining the western North Pacific anomalous anticyclone during El Niño to La Niña transition years. Climate Dyn., 46, 1027-1041, https://doi.org/10.1007/s00382-015-2630-1.

$-, \ldots, \ldots$, and Y. Du, 2017: Roles of tropical SST anomalies in modulating the western North Pacific anomalous cyclone during strong La Niña decaying years. Climate Dyn., 49, 633647, https://doi.org/10.1007/s00382-016-3364-4.

Chiang, J. C. H., L. M. Swenson, and W. Kong, 2017: Role of seasonal transitions and the westerlies in the interannual variability of the East Asian summer monsoon precipitation. Geophys. Res. Lett., 44, 3788-3795, https://doi.org/10.1002/ 2017GL072739.

Corbett, C. M., B. Subrahmanyam, and B. S. Giese, 2017: A comparison of sea surface salinity in the equatorial Pacific Ocean during the 1997-1998, 2012-2013, and 2014-2015 ENSO events. Climate Dyn., 49, 3513-3526, https://doi.org/10.1007/ s00382-017-3527-y.

Dee, D. P., and Coauthors, 2011: The ERA-Interim reanalysis: Configuration and performance of the data assimilation system. Quart. J. Roy. Meteor. Soc., 137, 553-597, https://doi.org/ 10.1002/qj.828.

Ding, Y. H., and J. C. L. Chan, 2005: The East Asian summer monsoon: An overview. J. Meteor. Soc. Japan, 89, 117-142, https://doi.org/10.1007/s00703-005-0125-z.

Dong, G., H. Zhang, A. Moise, L. Hanson, P. Liang, and H. Ye, 2016: CMIP5 model-simulated onset, duration and intensity of the Asian summer monsoon in current and future climate. Climate Dyn., 46, 355-382, https://doi.org/10.1007/s00382-0152588-z.

Durack, P., 2015: Ocean salinity and the global water cycle. Oceanography, 28, 20-31, https://doi.org/10.5670/oceanog. 2015.03.

Feng, J., W. Chen, C. Y. Tam, and W. Zhou, 2011: Different impacts of El Niño and El Niño Modoki on China rainfall in the decaying phases. Int. J. Climatol., 31, 2091-2101, https:// doi.org/10.1002/joc.2217.

Fu, Y. F., and G. S. Liu, 2003: Precipitation characteristics in midlatitude East Asia as observed by TRMM PR and TMI. J. Meteor. Soc. Japan, 81, 1353-1369, https://doi.org/10.2151/ jmsj.81.1353.

Gao, H., W. Jiang, and W. Li, 2015: Changed relationships between the East Asian summer monsoon circulations and the summer rainfall in eastern China. Acta Meteor. Sin., 28, 1075-1084, https://dx.doi.org/10.1007/s13351-014-4327-5.

Gong, D.-Y., and C. H. Ho, 2003: Arctic oscillation signals in the East Asian summer monsoon. J. Geophys. Res., 108, 40664066, https://doi.org/10.1029/2002JD002193.

Good, S. A., M. J. Martin, and N. A. Rayner, 2013: EN4: Quality controlled ocean temperature and salinity profiles and monthly objective analyses with uncertainty estimates. J. Geophys. Res. Oceans, 118, 6704-6716, https://doi.org/ 10.1002/2013JC009067.

Gordon, A., C. Giulivi, J. Busecke, and F. Bingham, 2015: Differences among subtropical surface salinity patterns. Oceanography, 28, 32-39, https://doi.org/10.5670/oceanog.2015.02.

Guo, Z., P. A. Dirmeyer, and T. Delsole, 2011: Land surface impacts on subseasonal and seasonal predictability. Geophys. Res. Lett., 38, L17808, https://doi.org/10.1029/ 2011 GL048611.

He, C., A. Lin, D. Gu, C. Li, B. Zheng, and T. Zhou, 2017: Interannual variability of eastern China summer rainfall: The origins of the meridional triple and dipole modes. Climate Dyn., 48, 683-696, https://doi.org/10.1007/s00382016-3103-x.

Hu, K., S.-P. Xie, and G. Huang, 2017: Orographically anchored El Niño effect on summer rainfall in central China. J. Climate, $\mathbf{3 0}$, 10 037-10 045, https://doi.org/10.1175/JCLI-D-17-0312.1.

Huang, R., and F. Sun, 1992: Impact of the tropical western Pacific on the East Asian summer monsoon. J. Meteor. Soc. Japan, 70, 243-256, https://doi.org/10.2151/jmsj1965.70.1B_243.

Kim, J.-E., and S.-Y.Hong, 2007: Impact of soil moisture anomalies on summer rainfall over East Asia: A regional climate model study. J. Climate, 20, 5732-5743, https://doi.org/10.1175/ 2006JCLI1358.1.

Koster, R. D., and Coauthors, 2004: Regions of strong coupling between soil moisture and precipitation. Science, 305, 11381140, https://doi.org/10.1126/science.1100217. 
Lau, K.-M., and M.-T. Li, 1984: The monsoon of East Asia and its global associations-A survey. Bull. Amer. Meteor. Soc., 65, 114-125, https://doi.org/10.1175/1520-0477(1984)065<0114: TMOEAA $>2.0 . \mathrm{CO} ; 2$

Li, L., R. W. Schmitt, C. C. Ummenhofer, and K. B. Karnauskas, 2016a: Implications of North Atlantic sea surface salinity for summer precipitation over the US Midwest: Mechanisms and predictive value. J. Climate, 29, 3143-3159, https://doi.org/ 10.1175/JCLI-D-15-0520.1.

,,--- , and $\longrightarrow, 2016 \mathrm{~b}$ : North Atlantic salinity as a predictor of Sahel rainfall. Sci. Adv., 2, e1501588, https:// doi.org/10.1126/sciadv.1501588.

,-- , and,- 2018 : The role of the subtropical North Atlantic water cycle in recent US extreme precipitation events. Climate Dyn., 50, 1291-1305, https://doi.org/10.1007/s00382017-3685-y.

Liu, L., R. Zhang, and Z. Zuo, 2017: Effect of spring precipitation on summer precipitation in eastern China: Role of soil moisture. J. Climate, 30, 9183-9194, https://doi.org/10.1175/JCLID-17-0028.1.

Liu, P., C. Y. Li, Y. Wang, and Y. F. Fu, 2013: Climatic characteristics of convective and stratiform precipitation over the tropical and subtropical areas as derived from TRMM PR. Sci. China Earth Sci., 56, 375-385, https://doi.org/10.1007/s11430012-4474-4.

Liu, T., R. W. Schmitt, and L. Li, 2018: Global search for autumnlead sea surface salinity predictors of winter precipitation in southwestern United States. Geophys. Res. Lett., 45, 84458454, https://doi.org/10.1029/2018GL079293.

Nagano, A., T. Hasegawa, I. Ueki, and K. Ando, 2017: El NiñoSouthern Oscillation-time scale covariation of sea surface salinity and freshwater flux in the western tropical and northern subtropical Pacific. Geophys. Res. Lett., 44, 6895-6903, https:// doi.org/10.1002/2017GL073573.

Pan, C., B. Zhu, J. Gao, and H. Kang, 2017: Source apportionment of atmospheric water over East Asia - a source tracer study in CAM5.1. Geosci. Model Dev., 10, 673-688, https://doi.org/ 10.5194/gmd-10-673-2017.

Saji, N. H., B. N. Goswami, P. N. Vinayachandran, and T. Yamagata, 1999: A dipole mode in the tropical Indian Ocean. Nature, 401, 360-363, https://doi.org/10.1038/43854.

Schar, C., D. Luthi, U. Beyerle, and E. Heise, 1999: The soilprecipitation feedback: A process study with a regional climate model. J. Climate, 12, 722-741, https://doi.org/10.1175/ 1520-0442(1999)012<0722:TSPFAP > 2.0.CO;2.

Schmitt, R. W., 1995: The ocean component of the global water cycle. Rev. Geophys., 33, 1395-1409, https://doi.org/10.1029/ 95RG00184.

- 2008: Salinity and the global water cycle. Oceanography, 21, 12-19, https://doi.org/10.5670/oceanog.2008.63.

Scipal, K., M. Drusch, and W. Wagner, 2008: Assimilation of a ERS scatterometer derived soil moisture index in the ECMWF numerical weather prediction system. Adv. Water Resour., 31, 1101-1112, https://doi.org/10.1016/j.advwatres.2008.04.013.

Sun, J., H. Wang, and W. Yuan, 2009: A possible mechanism for the co-variability of the boreal spring Antarctic Oscillation and the Yangtze River valley summer rainfall. Int. J. Climatol., 29, 1276-1284, https://doi.org/10.1002/joc.1773.

Wang, B., and LinHo, 2002: Rainy season of the Asian-Pacific summer monsoon. J. Climate, 15, 386-398, https://doi.org/ 10.1175/1520-0442(2002)015<0386:RSOTAP $>2.0 . C O ; 2$

- R. Wu, and X. Fu, 2000: Pacific-East Asian teleconnection: how does ENSO affect East Asian climate? J. Climate, 13
1517-1536, https://doi.org/10.1175/1520-0442(2000)013<1517: PEATHD $>2.0 . \mathrm{CO} ; 2$.

, Z. Wu, J. Li, J. Liu, C.-P. Chang, Y. Ding, and G. Wu, 2008: How to measure the strength of the East Asian summer monsoon. J. Climate, 21, 4449-4463, https://doi.org/10.1175/ 2008JCLI2183.1.

Webster, B. P. J., and S. Yang, 1992: Monsoon and ENSO: Selectively interactive systems. Quart. J. Roy. Meteor. Soc., 118, 877-926, https://doi.org/10.1002/qj.49711850705.

Wei, J., P. A. Dirmeyer, M. G. Bosilovich, and R. Wu, 2012: Water vapor sources for Yangtze River valley rainfall: Climatology, variability, and implications for rainfall forecasting. J. Geophys. Res., 117, D05126, https://doi.org/10.1029/ 2011JD016902.

Wu, Z., B. Wang, J. Li, and F.-F. Jin, 2009: An empirical seasonal prediction model of the East Asian summer monsoon using ENSO and NAO. J. Geophys. Res., 114, D18120, https:// doi.org/10.1029/2009JD011733.

Xiao, M., Q. Zhang, and V. P. Singh, 2015: Influences of ENSO, NAO, IOD and PDO on seasonal precipitation regimes in the Yangtze River basin, China. Int. J. Climatol., 35, 3556-3567, https://doi.org/10.1002/joc.4228.

Xie, P., 2010: CPC unified gauge-based analysis of global daily precipitation. 24th Conf. on Hydrology, Atlanta, GA, Amer. Meteor. Soc., 2.3A, https://ams.confex.com/ams/90annual/ webprogram/Paper163676.html.

Xie, S.-P., K. Hu, J. Hafner, H. Tokinaga, Y. Du, G. Huang, and T. Sampe, 2009: Indian Ocean capacitor effect on Indowestern Pacific climate during the summer following El Niño. J. Climate, 22, 730-747, https://doi.org/10.1175/ 2008JCLI2544.1.

, Y. Kosaka, Y. Du, K. Hu, J. S. Chowdary, and G. Huang, 2016: Indo-western Pacific Ocean capacitor and coherent climate anomalies in post-ENSO summer: A review. $A d v$. Atmos. Sci., 33, 411-432, https://doi.org/10.1007/s00376-0155192-6.

Xue, Y. K., H. M. H. Juang, W. P. Li, S. Prince, R. DeFries, Y. Jiao, and R. Vasic, 2004: Role of land surface processes in monsoon development: East Asia and West Africa. J. Geophys. Res., 109, D03105, https://doi.org/10.1029/2003JD003556.

Yang, S., and K. M. Lau, 1998: Influences of sea surface temperature and ground wetness on Asian summer monsoon. J. Climate, 11, 3230-3246, https://doi.org/10.1175/15200442(1998)011<3230:IOSSTA > 2.0.CO;2.

Ye, H., and R. Lu, 2012: Dominant patterns of summer rainfall anomalies in East China during 1951-2006. Adv. Atmos. Sci., 29, 695-704, https://doi.org/10.1007/s00376012-1153-5.

Yu, L., 2011: A global relationship between the ocean water cycle and near-surface salinity. J. Geophys. Res., 116, C10025, https://doi.org/10.1029/2010JC006937.

, X. Jin, S. A. Josey, T. Lee, A. Kumar, C. Wen, and Y. Xue, 2017: The global ocean water cycle in atmospheric reanalysis, satellite, and ocean salinity. J. Climate, 30, 3829-3852, https:// doi.org/10.1175/JCLI-D-16-0479.1.

Zeng, L., R. W. Schmitt, L. Li, Q. Wang, and D. Wang, 2019: Forecast of summer precipitation in the Yangtze River valley based on South China Sea springtime sea surface salinity. Climate Dyn., https://doi.org/10.1007/s00382-019-04878-y, in press.

Zhang, J., L. Wu, and W. Dong, 2011: Land-atmosphere coupling and summer climate variability over East Asia. J. Geophys. Res., 116, D05117, https://doi.org/10.1029/2010JD014714. 
Zhang, L., and T. Zhou, 2015: Drought over East Asia: A review. J. Climate, 28, 3375-3399, https://doi.org/10.1175/JCLI-D-1400259.1.

Zhong, S., T. Yang, Y. Qian, J. Zhu, and F. Wu, 2018: Temporal and spatial variations of soil moisture-precipitation feedback in East China during the East Asian summer monsoon period: A sensitivity study. Atmos. Res., 213, 163-172, https://doi.org/ 10.1016/j.atmosres.2018.05.014.

Zhou, T. J., and R. C. Yu, 2005: Atmospheric water vapor transport associated with typical anomalous summer rainfall patterns in
China. J. Geophys. Res., 110, D08104, https://doi.org/10.1029/ 2004JD005413.

Zuo, Z., and R. Zhang, 2009: Temporal and spatial features of the soil moisture in boreal spring in eastern China. Sci. China, 52D, 269-278, https://doi.org/10.1007/s11430-0090011-5.

_ , and —_, 2016: Influence of soil moisture in eastern China on the East Asian summer monsoon. Adv. Atmos. Sci., 33, 151-163, https://doi.org/10.1007/s00376-0155024-8. 